\title{
A word of caution regarding patients with hypoplastic left heart syndrome and a diminutive aorta
}

\author{
Christian Schreiber, MD, PhD, ${ }^{\mathrm{a}}$ Zsolt Prodan, MD, ${ }^{\mathrm{a}}$ Jelena Kasnar-Samprec, MD, ${ }^{\mathrm{a}}$ Richard Henze, MD, ${ }^{\mathrm{b}}$ and \\ Rüdiger Lange, $\mathrm{MD}, \mathrm{PhD},{ }^{\mathrm{a}}$ Munich, Germany
}

We report the case of a patient with a diminutive aorta who had an obstruction at the site of the aortic anastomosis with the pulmonary trunk at second-stage palliation. Caution in the case of a small aorta seems warranted, because on regular preoperative assessment before second-stage palliation, no irregularity in coronary blood supply was detected. Only a detailed echocardiographic assessment revealed the potentially life-threatening aortic stenosis.

\section{CLINICAL SUMMARY}

A 4-month-old patient with hypoplastic left heart syndrome and aortic atresia was admitted electively for second-stage palliation. Previously, at a body weight of $3 \mathrm{~kg}$, the patient had undergone neoaortic reconstruction, incorporating the ascending aorta by side-to-side anastomosis. At the heel of this side-by-side anastomosis, absorbable sutures were used. The augmentation of the neoaorta was completed with a homograft patch.

Before elective second-stage palliation, angiography revealed a somewhat narrowed ostium toward the native ascending aorta (Figure 1, A). It is of note, however, that the ascending aorta initially had an internal diameter of just $1.5 \mathrm{~mm}$ (Figure 1,B). Interestingly, no signs of any malperfusion of the heart were observed on electrocardiography. Intraoperative echocardiography, however, clearly revealed a flow impairment (Figure 2, A). Ventricular function was reduced. After resternotomy and crossclamping, the neoaorta was opened. The ostium toward the native ascending aorta measured just $2 \mathrm{~mm}$. After incision of the wall between the native ascending aorta and the former pulmonary trunk and plication of the incision edges with 7-0 sutures, an additional GORE-TEX (W.L. Gore \& Associates, Flagstaff, Ariz) patch was used to augment the ostial site (Figure 2, B). Finally, a cavopulmonary anastomosis

From the Clinic of Cardiovascular Surgery ${ }^{\mathrm{a}}$ and the Department of Anesthesiology, ${ }^{\mathrm{b}}$ German Heart Center Munich at the Technical University Munich, Munich, Germany.

Received for publication Nov 29, 2007; accepted for publication Dec 3, 2007.

Address for reprints: Christian Schreiber, MD, PhD, Clinic of Cardiovascular Surgery, German Heart Center Munich at the Technical University Munich, Lazarettstrasse 36, 80636 Munich, Germany (E-mail: schreiber@dhm.mhn.de).

J Thorac Cardiovasc Surg 2008;136:1596-7

$0022-5223 / \$ 34.00$

Copyright (C) 2008 by The American Association for Thoracic Surgery doi:10.1016/j.jtcvs.2007.12.060 was accomplished on the beating heart. The patient's recovery was uneventful. Ventricular function improved, and echocardiographic investigation revealed unobstructed flow into the native aorta.

\section{DISCUSSION}

Ilbawi and coworkers ${ }^{1}$ recently quantified the presence and degree of narrowed areas within diminutive ascending aorta in hypoplastic left heart syndrome specimens. Their findings support the importance of incorporating the ascending aorta into aortic reconstruction at the time of initial palliation for hypoplastic left heart syndrome. Extending the incision to the proximal ascending aorta eliminates most areas of narrowing, increases the blood flow and pressure, and allows for aortic growth. Mahle and colleagues ${ }^{2}$ have confirmed that adjacent tissue grows after side-to-side anastomosis.

Another strategy includes transection of the ascending aorta and end-to-side anastomosis to the neoaorta. The main drawback of not incorporating the ascending aorta is that coronary perfusion remains dependent on retrograde flow through long, narrow, and potentially obstructed aortic segments. The study of Forbess and associates ${ }^{3}$ found that with this technique the risk of compromise to coronary arterial flow after 10 years was increased. ${ }^{3}$

In our institution, we to date have opted only for incorporation of the ascending aorta in the neoaorta. Several technical steps may help to decrease the occurrence of the described obstruction. The native ascending aorta should be opened as proximally as possible. A V-shaped incision into the proximal opening of the aorta then allows a slightly wider anastomosis. The homograft patch should be tailored to cause neither tension nor distortion.

To date, we have not encountered immediate intraoperative or early postoperative complications related to compromised coronary blood flow, even among the rare patients with an ascending aorta diameter smaller than $2 \mathrm{~mm}$. This case, however, highlights the need for careful postoperative monitoring. It seems prudent to rule out any flow obstructions at the site of the anastomosis to the native ascending aorta, and not only just before the second-stage palliative procedure. Angiography may not give all the information required, whereas echocardiography allows detection of even slightly impaired coronary flow. 

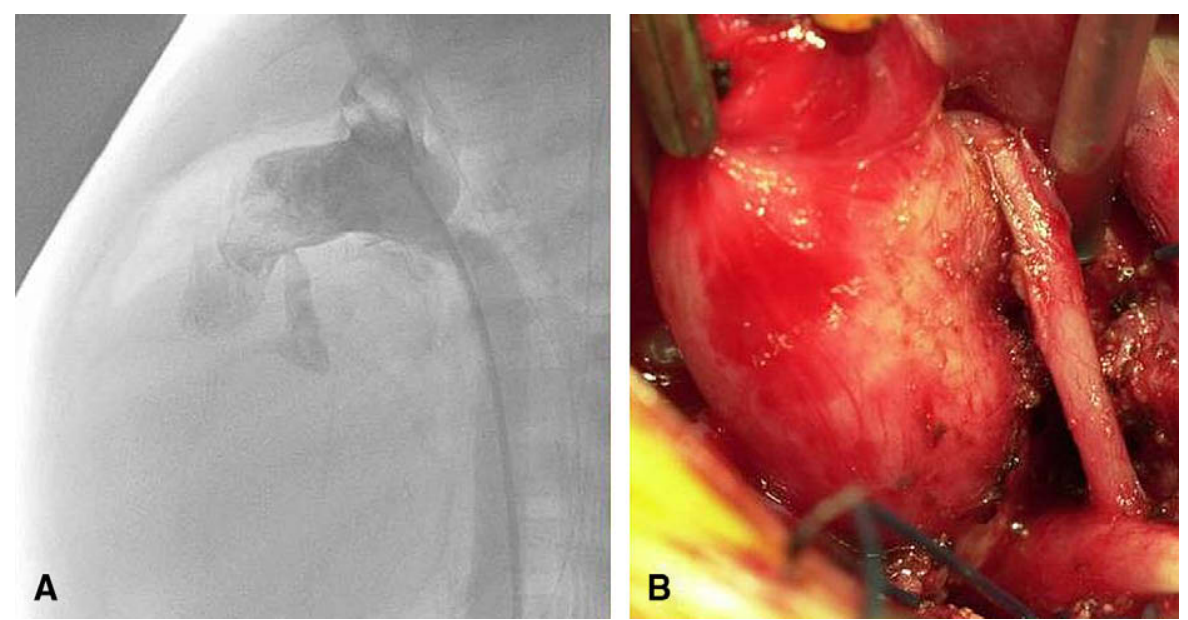

FIGURE 1. A, Intraoperative image showing diminutive aorta. B, Angiogram revealing narrowed ostium to native ascending aorta.
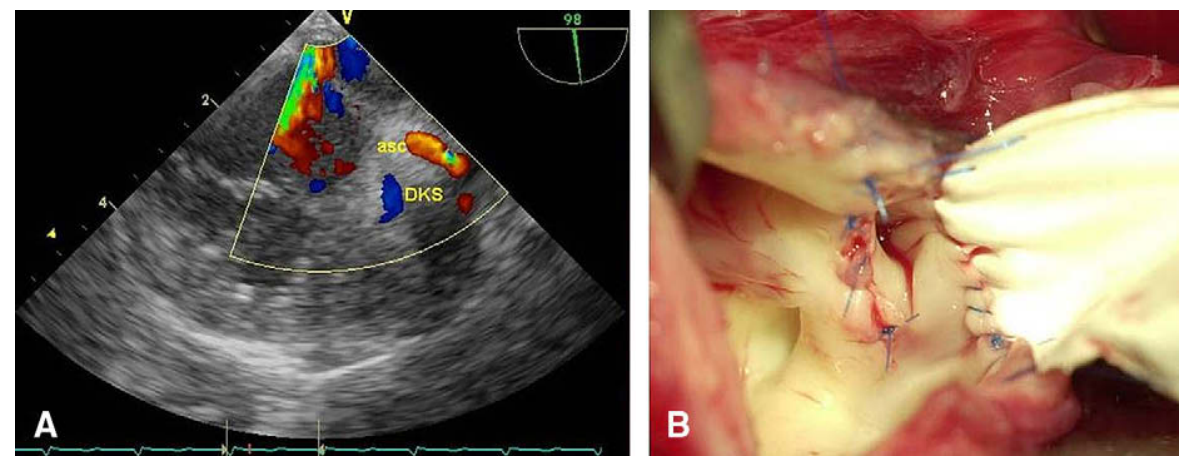

FIGURE 2. A, Echocardiography proving flow impairment into native ascending aorta. Asc, Native ascending aorta; DKS, Damus-Kaye-Stansel. B, Enlargement of ostial site by incision and patch plasty.

\section{References}

1. Ilbawi AM, Spicer DE, Bharati S, Cook A, Anderson RH. Morphologic study of the ascending aorta and aortic arch in hypoplastic left hearts: surgical implications. $J$ Thorac Cardiovasc Surg. 2007;134:99-105.

2. Mahle WT, Rychik J, Weinberg PM, Cohen MS. Growth characteristics of the aortic arch after the Norwood operation. J Am Coll Cardiol. 1998;32:1951-4.
3. Forbess JM, Cook N, Roth SJ, Serraf A, Mayer JE Jr, Jonas RA. Ten-year institutional experience with palliative surgery for hypoplastic left heart syndrome. Risk factors related to stage I mortality. Circulation. 1995; 92(9 Suppl):II262-6.

\section{Artificial chordae: A simple clip and tie technique}

Daniel T. L. Chan, MBBS, Clement S. W. Chiu, MBBS, FRCS, L. C. Cheng, MBBS, FRCS, and Timmy W. K. Au, MBBS, FRCS,

Hong Kong, China

\footnotetext{
From the Cardiothoracic Surgical Unit, Grantham Hospital, Hong Kong SAR, China. Received for publication Dec 4, 2007; accepted for publication Dec 8, 2007.

Address for reprints: Timmy W. K. Au, MBBS, FRCS, 3/F CTSU, Grantham Hospital,

Wong Chuk Hang, Hong Kong SAR, China (E-mail: auwingkuk@yahoo.com.hk). J Thorac Cardiovasc Surg 2008;136:1597-9

$0022-5223 / \$ 34.00$

Copyright (c) 2008 by The American Association for Thoracic Surgery

doi:10.1016/j.jtcvs.2007.12.080
}

Mitral regurgitation caused by anterior leaflet prolapse can be repaired with resupporting neochordae made from expanded polytetrafluoroethylene (Gore-Tex; W.L. Gore \& Associates, Inc, Flagstaff, Ariz) sutures. This technique has been shown in various series to have excellent longterm results. ${ }^{1}$ Technical difficulties, however, may be encountered when measuring the correct length and tying 